\title{
Cerebellar Exposure to Cell-Free Hemoglobin Following Preterm Intraventricular Hemorrhage: Causal in Cerebellar Damage?
}

\author{
Alex Adusei Agyemang ${ }^{1} \cdot$ Kristbjörg Sveinsdóttir $^{1} \cdot$ Suvi Vallius ${ }^{1}$. \\ Snjolaug Sveinsdóttir ${ }^{1}$ - Matteo Bruschettini ${ }^{1}$ - Olga Romantsik ${ }^{1}$ - Ann Hellström ${ }^{2}$. \\ Lois E. H. Smith ${ }^{3} \cdot$ Lennart Ohlsson $^{4} \cdot$ Bo Holmqvist $^{5}$ - Magnus Gram ${ }^{1,6} \cdot$ David Ley $^{1}$
}

Received: 2 March 2017 / Accepted: 9 May 2017 / Published online: 10 June 2017

(C) The Author(s) 2017. This article is an open access publication

\begin{abstract}
Decreased cerebellar volume is associated with intraventricular hemorrhage (IVH) in very preterm infants and may be a principal component in neurodevelopmental impairment. Cerebellar deposition of blood products from the subarachnoid space has been suggested as a causal mechanism in cerebellar underdevelopment following IVH. Using the preterm rabbit pup IVH model, we evaluated the effects of IVH induced at E29 (3 days prior to term) on cerebellar development at term-equivalent postnatal day $0(\mathrm{P} 0)$, term-equivalent postnatal day 2 (P2), and term-equivalent postnatal day 5 (P5). Furthermore, the presence of cell-free hemoglobin $(\mathrm{Hb})$ in cerebellar tissue was characterized, and cell-free $\mathrm{Hb}$ was evaluated as a causal factor in the development of cerebellar damage following preterm IVH. IVH was associated with a decreased proliferative (Ki67-positive) portion of the external granular layer (EGL), delayed Purkinje cell maturation, and
\end{abstract}

Electronic supplementary material The online version of this article (doi:10.1007/s12975-017-0539-1) contains supplementary material, which is available to authorized users.

David Ley

david.ley@med.lu.se

1 Pediatrics, Department of Clinical Sciences Lund, Skåne University Hospital, Lund University, BMC C14, SE-221 84 Lund, Sweden

2 Department of Ophthalmology, Institute of Neuroscience and Physiology, Sahlgrenska Academy, University of Gothenburg, Gothenburg, Sweden

3 Department of Ophthalmology, Boston Children's Hospital, Harvard Medical School, Boston, MA, USA

4 MicroMorph Histology Services, Lund, Sweden

5 ImaGene-iT AB, Medicon Village, Lund, Sweden

6 Infection Medicine, Department of Clinical Sciences Lund, Lund University, Lund, Sweden activated microglia in the cerebellar white matter. In pups with $\mathrm{IVH}$, immunolabeling of the cerebellum at $\mathrm{P} 0$ demonstrated a widespread presence of cell-free $\mathrm{Hb}$, primarily distributed in the white matter and the molecular layer. Intraventricular injection of the $\mathrm{Hb}$ scavenger haptoglobin $(\mathrm{Hp})$ resulted in a corresponding distribution of immunolabeled $\mathrm{Hp}$ in the cerebellum and a partial reversal of the damaging effects observed following IVH. The results suggest that cell-free $\mathrm{Hb}$ is causally involved in cerebellar damage following IVH and that blocking cell-free $\mathrm{Hb}$ may have protective effects.

Keywords Intraventricular hemorrhage $\cdot$ Hemoglobin Haptoglobin $\cdot$ Cerebellum $\cdot$ External granular layer

\section{Introduction}

Cerebral intraventricular hemorrhage (IVH) continues to be a serious complication of preterm birth, resulting in a high incidence of neurodevelopmental impairment, including cerebral palsy and intellectual disability [1]. During the past decades, neurological impairment following very preterm birth has primarily been considered to originate in cerebral white matter lesions [2, 3], but recent findings have also linked neurological deficits of preterm birth to cerebellar abnormalities $[4,5]$. Prevalence of cerebellar injury has been described to be as high as $58 \%$ in infants with cerebral palsy following IVH and preterm birth [6].

From gestational weeks 20 to 40 , the cerebellum undergoes an unparalleled growth with a volumetric increase from approximately 1 to $25 \mathrm{~cm}^{3}$ [7]. This rapid growth renders the cerebellum very sensitive to injury $[8,9]$. Cerebellar underdevelopment may ensue from a direct cerebellar injury, such as hemorrhage or infarction, or from a secondary effect related to damage at a remote but connected area of the brain [10]. 
Cerebellar hypoplasia has repeatedly been shown to be associated with supratentorial IVH in very preterm infants and is a potential component in neurological disability $[9,11,12]$. Of note, the severity of IVH is linked to the degree of impaired cerebellar development in preterm infants, with cerebellar volume at term age being inversely correlated with increasing severity of IVH [7].

In clinical studies, MRI at term age shows infratentorial hemosiderin deposits in $70 \%$ of preterm infants with IVH and disrupted cerebellar development. The deposits are prominent not only on the cerebellar surface but also on the surface of the brain stem and in the region of the fourth ventricle. This hemosiderin deposition is the most predictive factor for impairment in cerebellar development and thus is suggested as a plausible causal mechanism of cerebellar hypoplasia following preterm IVH [9].

The neurotoxicity of cell-free hemoglobin $(\mathrm{Hb})$ and its metabolites has been reported after intraventricular, intraparenchymal, and subarachnoid hemorrhage (SAH) [13-20]. Cell-free $\mathrm{Hb}$ and its metabolites free heme, iron, reactive oxygen species (ROS), and free radicals can be highly damaging to cells, lipids, proteins, and DNA through oxidative modification, fragmentation, and cross-linking [21-23]. Cell-free $\mathrm{Hb}$ and its metabolites can induce cytotoxic, oxidative, and inflammatory pathways in the cerebrospinal fluid (CSF) and choroid plexus ependyma leading to tissue damage and cell death following preterm rabbit pup IVH [17-19]. Furthermore, a high accumulation of cell-free $\mathrm{Hb}$ in the periventricular white matter has been observed following hemorrhage in the rabbit pup IVH model [20].

In this study, we have completed the first investigation of the exposure of the developing cerebellum to cell-free $\mathrm{Hb}$ following preterm IVH and the potentially damaging effect on cerebellar development. Furthermore, we report on the protective effects of the $\mathrm{Hb}$ scavenger haptoglobin (Hp) following intraventricular administration. Results show that after IVH, key cell populations of the developing cerebellum are exposed to cell-free $\mathrm{Hb}$, which may be central in the pathophysiological events leading to cerebellar underdevelopment.

\section{Materials and Methods}

\section{Animals}

The study was approved by the Swedish Animal Ethics Committee in Lund. We used the well-established preterm rabbit pup model of glycerol-induced IVH as previously described [24]. The study included 59 rabbit pups from 9 litters delivered at gestational day 29 (full term corresponding to 32 days) $[25,26]$. A half-breed between New Zealand White and Lop was used. The pups were delivered by caesarean section after the does were anesthetized with i.v. propofol
$(5 \mathrm{mg} / \mathrm{kg})$ and with local infiltration of the abdominal wall using lidocaine with adrenaline $(10 \mathrm{mg} / \mathrm{ml}+5 \mu \mathrm{l} / \mathrm{ml}, 20$ $30 \mathrm{ml}$ ). After delivery, the pups were dried, weighed, and placed in an infant incubator set to a temperature of 34 $35{ }^{\circ} \mathrm{C}$ and ambient humidity. At $2 \mathrm{~h}$ of age, the pups were hand-fed with $2 \mathrm{ml}(100 \mathrm{ml} / \mathrm{kg} /$ day $)$ of kitten milk formula (KMR; PetAg Inc., Hampshire, IL, USA) using a 3.5 French feeding tube and fed every $12 \mathrm{~h}$ increasing each meal by $1 \mathrm{ml}$. At $2 \mathrm{~h}$ of age, the pups were injected intraperitoneally with $50 \%(\mathrm{v} / \mathrm{v})$ sterile glycerol $(6.5 \mathrm{~g} / \mathrm{kg}$; Teknova, Hollister, CA, USA) to induce IVH. Ultrasound imaging of the brain was performed at $6 \mathrm{~h}$ of age to grade the severity of the IVH and detect SAH and daily thereafter using the VisualSonics Vevo 2100 (VisualSonics Inc., ON, Canada) with a MS-550D $40 \mathrm{MHz}$ transducer. Animals with IVH at $6 \mathrm{~h}$ were included in the IVH group, and those without detectable IVH at all time points were used as controls (denoted as sham control). The reproducibility and accuracy of high-frequency ultrasound in this animal model have been described previously [24].

\section{Intraventricular Injections}

After the initial ultrasound examination at $6 \mathrm{~h}$ of age, pups with IVH (presence of blood within distended lateral ventricles and no sign of parenchymal involvement) were randomized into one of the following three groups: IVH, IVH $+\mathrm{Hp}$, or IVH + Vehicle. Pups in the IVH + Hp and IVH + Vehicle groups received an ultrasound-guided intraventricular injection at $8 \mathrm{~h}$ of age of either $20 \mu \mathrm{l}$ of human $\mathrm{Hp}(50 \mathrm{mg} / \mathrm{ml}$, Bio Products Laboratory, London, UK) or $20 \mu$ of vehicle solution $(9 \mathrm{mg} / \mathrm{ml} \mathrm{NaCl}$, Fresenius Kabi, Lake Zurich, IL, USA), using 27 G Hamilton syringes (Hamilton Robotics, Reno, NV, USA). The efficacy and accuracy of this method have been described previously [26]. The animals were euthanized at the following time points: $72 \mathrm{~h}$ ( $\mathrm{P} 0$, corresponding to term-equivalent postnatal day 0$), 120 \mathrm{~h}(\mathrm{P} 2$, corresponding to term-equivalent postnatal day 2 ), or $192 \mathrm{~h}$ (P5, corresponding to term-equivalent postnatal day 5) of age. Cerebellar tissues were sampled and processed as described below. An overview of the study design is given in Fig. 1.

\section{Tissue Collection and Processing}

Following sedation with isoflurane inhalation, perfusion fixation of the brain was performed at P0 and P5 by cardiac cannulation following thoracotomy and infusion of $0.9 \%$ saline followed by $4 \%$ paraformaldehyde (PFA, buffered with phosphate buffer saline (PBS) $0.1 \mathrm{M}, \mathrm{pH}$ 7.4). After completed perfusion, the cerebrum and cerebellum were carefully extracted from the skulls and immersed in 4\% PFA for a total of $48 \mathrm{~h}$. SAH was confirmed in all pups with IVH with visible presence of hemorrhagic CSF covering the cerebellar cortex. None of the control pups exhibited macroscopic signs of 


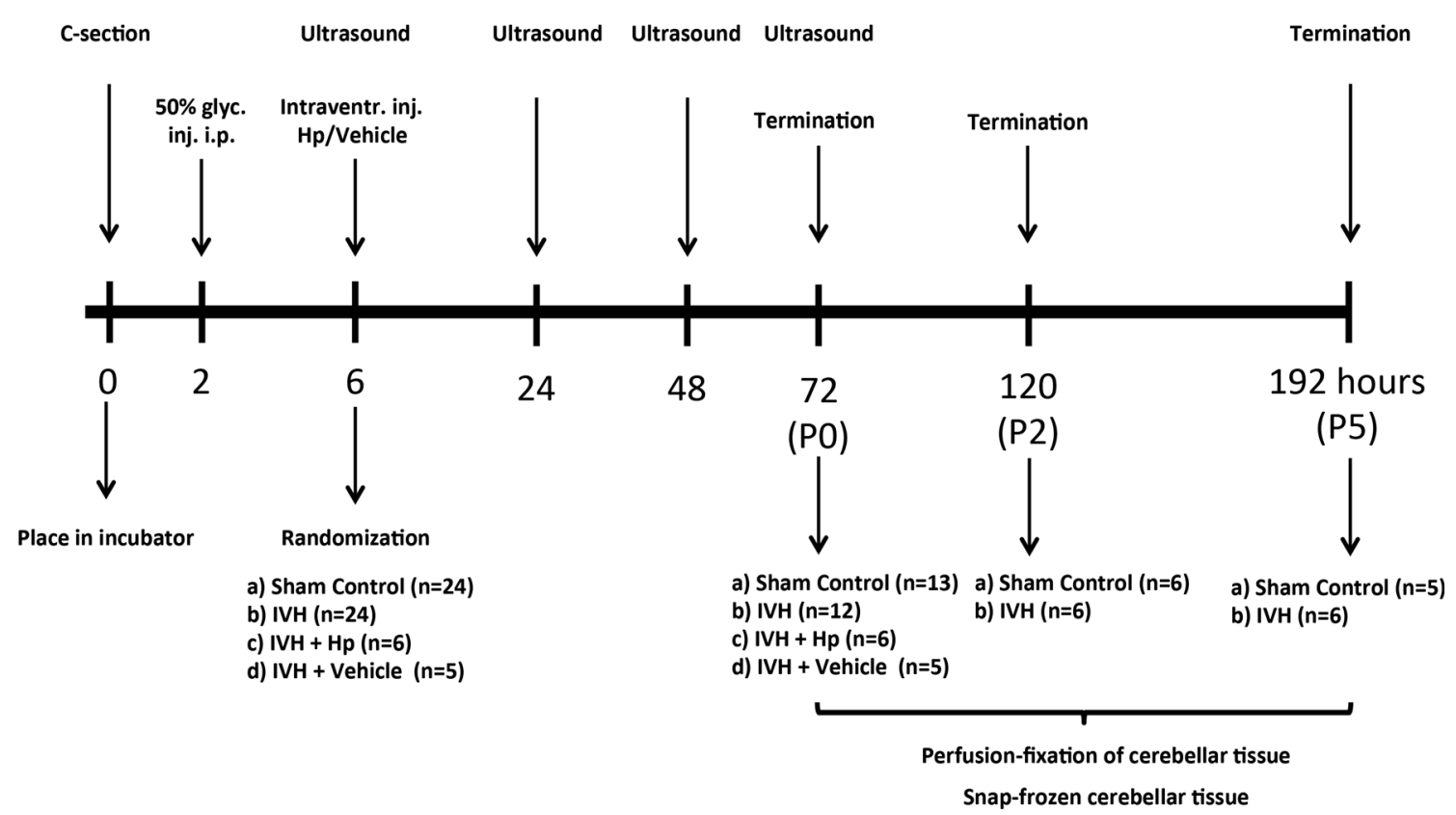

Fig. 1 Study outline. A diagram summarizing the experimental procedure. The experiment consisted of the following steps: preterm delivery of rabbit pups by caesarean section, induction of IVH by intraperitoneal glycerol administration, verification of IVH or sham

SAH. A change to fresh PFA was performed after 3-6 h. Thereafter, the tissues were dehydrated, cleared, infiltrated with paraffin, and embedded in paraffin blocks. The cerebellum was sectioned into 4- $\mu \mathrm{m}$ sections (Leica, RM2255 Microtome) in the parasagittal plane at the level of the dentate nucleus and mounted on microscope slides and dried at $37^{\circ} \mathrm{C}$ for 12-16 h. None of the cerebellar samples in pups with IVH or in control pups exhibited signs of primary cerebellar hemorrhage. Prior to antibody staining for immunohistochemistry (IHC), the sections were rehydrated, followed by heat-induced antigen retrieval at $90-95{ }^{\circ} \mathrm{C}$ for 20 min either in boric acid buffer (pH 8.0) for labeling of Ki67, calbindin, and Ibal or in citric acid (pH 6.0, with $0.05 \%$ Tween 20 or $0.2 \%$ Triton X) for 10-20 min for immunofluorescence labeling of $\mathrm{Hb}$ and Hp.

\section{Immunofluorescence Labeling}

Immunofluorescence labeling of $\mathrm{Hb}$ was performed to investigate the presence and distribution of both encapsulated erythrocytes and cell-free $\mathrm{Hb}$ within the cerebellum. Double immunofluorescence labeling of $\mathrm{Hb}$ together with human $\mathrm{Hp}$ was performed to simultaneously visualize $\mathrm{Hb}$ and $\mathrm{Hp}$ to elucidate whether the intraventricularly injected human Hp could reach the cerebellar brain regions containing $\mathrm{Hb}$ (preferentially the cell-free $\mathrm{Hb}$ ) in the IVH rabbit pups.

In brief, the immunofluorescence labeling protocol was carried out as described below. Following antigen retrieval, sections were immersed in PBS $(2 \times 5 \mathrm{~min})$,

control by the use of high-frequency ultrasound, randomization into study groups, intraventricular administration of $\mathrm{Hp}$ or vehicle solution, termination of pups, and collection of cerebellar tissue. For details about each step, see "Materials and Methods"

encircled with silicon (PAP-pen, Sakura, Tokyo, Japan), and then blocked with $1 \%$ bovine serum albumin (BSA) in PBS containing $0.05 \%$ Triton $\mathrm{X}(\mathrm{PBST} \times \mathrm{BSA})$ for $60 \mathrm{~min}$ at room temperature (RT). This step was followed by $16 \mathrm{~h}$ of incubation at $4{ }^{\circ} \mathrm{C}$ with either one of the primary antibodies or a mixture of the two primary antibodies diluted in PBST $\times$ BSA. All antibody incubations were performed in a moisture chamber. Primary antibodies used were against $\mathrm{Hb}$, made in goat (diluted 1:500), and against human $\mathrm{Hp}$, made in chicken (diluted 1:1000), both from GenWay Biotech, Inc. (San Diego, CA, USA) and diluted in PBST $\times$ BSA. Sections were then rinsed in PBS $(3 \times 3 \mathrm{~min})$, followed by incubation for $60 \mathrm{~min}$ at RT with one secondary antibody made against goat $\mathrm{IgG}$ or with a mixture of secondary antibodies made against goat $\operatorname{IgG}$ and chicken $\operatorname{IgY}$ (diluted 1:200 in PBST $\times$ BSA). The secondary antibodies were both affinity-purified Fab2 fragments for multi-labeling, made in donkey (Jackson ImmunoResearch, West Grove, PA, USA). The anti-chicken IgY was conjugated with Alexa Fluor 488 (AF488) and the goat IgG conjugated with Rhodamine Red (rhodamine). Sections were then rinsed in PBS $(3 \times 3 \mathrm{~min})$ and incubated in DAPI $(0.1 \mu \mathrm{M}$, diluted in PBS, Invitrogen, Rockford, IL, USA) for $30 \mathrm{~min}$ at RT. After being rinsed in PBS $(3 \times 3 \mathrm{~min})$, sections were mounted (Fluoroshield, Abcam, England, ab104135) and cover-slipped. All animal groups were always processed together in the same immunolabeling experiment. 


\section{Antibody Control for Immunofluorescence Labeling}

Antibody specificity tests were performed on parallel sections in all labeling experiments; in these tests, the primary antibodies were excluded from the labeling protocol (Fig. 1 in the Data supplement). This control confirmed that the visualized and documented $\mathrm{Hb}$ and $\mathrm{Hp}$ immunofluorescence labeling (Fig. 2) was caused by binding of the respective primary antibodies and was not the result of binding of secondary antibodies or autofluorescence. All tested samples showed no $\mathrm{Hb}$ or Hp labeling within the cerebellum (see Fig. 1 in the Data supplement). Autofluorescence was solely obtained from whole cell bodies, from erythrocytes/RBCs in the subarachnoid space preferentially, and occasionally from some neuronal cell bodies. Thus, the antibody controls showed that both primary and secondary antibodies bind to their targets in the immunofluorescence labeling protocol applied here, supporting their specific detection of rabbit $\mathrm{Hb}$ and human $\mathrm{Hp}$, visualized as extracellular (cell-free) and in whole erythrocytes.

\section{Analyses of the Distribution of $\mathrm{Hb}$ and Its Relation to $\mathrm{Hp}$}

The anatomical distribution of the double immunofluorescence-labeled $\mathrm{Hb}$ and $\mathrm{Hp}$ was analyzed using a wide-field epi-fluorescence microscope (Olympus IX73, Shinjuku, Tokyo, Japan). Analysis of the double labeling was performed by switching between the specific filter sets used for each fluorophore, DAPI for cell nuclei (blue), rhodamine for $\mathrm{Hb}$ (red), and AF488 for $\mathrm{Hp}$ (green), together with digital image documentation (Olympus DP80). The separate images for each channel (fluorophore) were merged for detailed analyses of double labeling to identify them as coexisting or not (see representative images in Fig. 2). To ensure sole detection of primary antibody binding, i.e., excluding detection of autofluorescence or of nonspecific secondary antibody binding, the detection level (threshold) for each channel was always set from sections with antibody controls (see above) and from sections from control animals that had been taken through the whole labeling protocol. Analyses and digital imaging were performed with the preset detection levels (detection intensities solely from specific labeling) for each channel. The relatively strong autofluorescence from cell bodies, mainly from RBCs, could be clearly separated from the non-cell body-associated, cell-free, and widely distributed $\mathrm{Hb}$ in IVH animals and together with $\mathrm{Hp}$ in IVH animals that received Hp (see Fig. 2).

\section{Immunohistochemistry of Cerebellar Development and Reactive Microgliosis}

To investigate the effect of IVH on the cerebellum of preterm rabbit pups, IHC labeling against the following antigens was performed: (1) Ki67, to evaluate cellular proliferation; (2) calbindin, to evaluate Purkinje cell development and maturation; and (3) Iba1, to evaluate microglial activation. Qualitative and quantitative analysis at P0, P2, and P5 were performed. Briefly, the protocol was as follows. After antigen retrieval and rinsing in PBS, sections were incubated with primary antibodies (diluted in PBS $+5 \%$ normal goat serum, Jackson ImmunoResearch, 005-000-121) for $1 \mathrm{~h}$ at RT. Primary antibodies were made against rabbit Ki67 (mouse IgG anti-Ki67, Dako, Copenhagen, Denmark), calbindin (mouse IgG anti-calbindin, DBS, Pleasanton, CA), and Iba1 (rabbit IgG anti-Iba1, Biocare, Concord, CA). Sections were then rinsed in PBS $(3 \times 2 \mathrm{~min})$. To detect the primary antibody, sections were incubated with either BrightVision rabbit/ horseradish peroxidase (HRP) or BrightVision mouse/HRP (DPVR110HRP or DPVM110HRP, both from Immunogen) for $30 \mathrm{~min}$ at RT. Sections were then rinsed in Tris $(0.05 \mathrm{M}$, $\mathrm{pH}$ 7.6, $3 \times 2 \mathrm{~min}$ ). To visualize the HRP conjugations, sections were incubated with a diaminobenzidine (DAB; $50 \mathrm{mg}$ DAB, Sigma, dissolved in $100 \mathrm{ml}$ Tris buffer, $\mathrm{pH}$ 7.6, $3 \times 2 \mathrm{~min}$ ) and $100 \mu \mathrm{l}$ of hydrogen peroxide (Merck, prepared just prior to incubation) solution was added for $5 \mathrm{~min}$ at RT. After rinsing in Tris $(3 \times 2 \mathrm{~min})$, hematoxylin staining of cell nuclei (Mayers HTX, Bio-Optica) was performed for $5 \mathrm{~s}$, after which the sections were dehydrated and slides were then mounted with coverslips (X-Tra-Kitt, Medite, Burgdorf, Germany). Antibody specificity tests were performed on parallel sections to confirm that the visualized immunostaining was specific for the primary antibodies. In these tests, the primary antibodies were excluded from the labeling protocol (Fig. 2 in the Data supplement). Analysis and image documentation for the results of qualitative and quantitative analysis (see below) of IHC labeling were performed with a brightfield microscope (Leica DMRX), equipped with a digital camera (Leica MC120HD).

Measurement of the width $(\mu \mathrm{m})$ of the proliferative external granular layer (EGL), as determined by Ki67-positive cells, was performed in four predefined regions. These regions were the inner and outer portions of lobule $V$ and the inner and outer portions of lobule IX, respectively, as illustrated in Fig. 3 in the Data supplement. These regions were chosen because they represent regions with possible maturational differences in EGL proliferation and subsequent width. Measurements were performed with a bright-field microscope (Leica DMRX), using a $\times 40$ dry objective lens. The average of the four respective measured widths was calculated for each pup.

Using the Leica Q500 image analysis system of the microscope, the areas of Iba1- and calbindin-positive stained cells were respectively determined in relation to the cerebellar white matter area and the area of the molecular layer. Thus, both positive Ibal and calbindin staining were expressed as percentage positive area in relation to, respectively, a standardized area of the cerebellar white matter and of the 

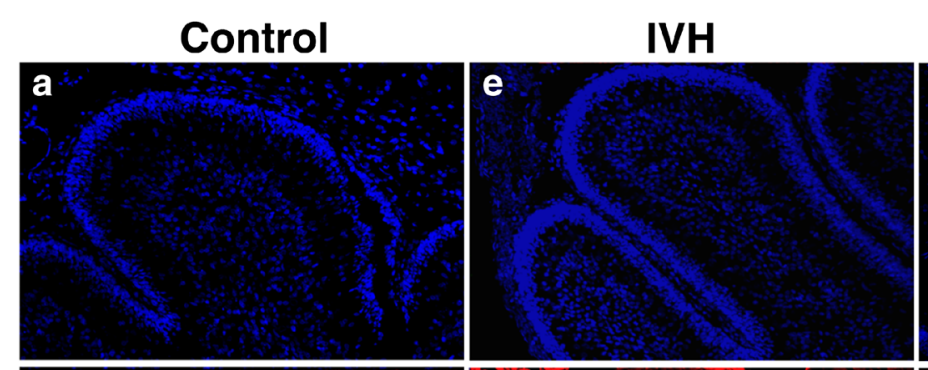

\section{IVH + Haptoglobin}


Fig. 2 Immunofluorescence labeling of $\mathrm{Hb}$ and the administered human $\mathrm{Hp}$. Representative images are from rabbit pups at P0. Images illustrate the detected immunofluorescence labeling, performed by double immunofluorescence labeling of $\mathrm{Hb}$ (red) and $\mathrm{Hp}$ (green) together with a DAPI nuclear staining (blue), in animals with no IVH (Control), in animals with IVH $(I V H)$, and in animals with IVH that received human Hp injections $(I V H+$ Haptoglobin $)$. Antibody specificity tests showed that the antibodies against $\mathrm{Hb}$ and human $\mathrm{Hp}$ bound to their true targets (see Fig. 1 in the Data supplement). a-d Control animal: Images $\mathbf{b}$ and $\mathbf{c}$ show the lack of $\mathrm{Hb}$ and Hp labeling and the autofluorescence mainly from whole erythrocytes (RBCs) restricted to the subarachnoid space and some blood vessels (d). eh IVH: In pups with IVH, the Hb labeling (red) was extensive, widely distributed in the molecular layer and white matter and to some degree in the EGL. Whole erythrocytes in the subarachnoid space surrounding the cerebellar lobuli were also intensely labeled and gave rise to green autofluorescence (g), observed as yellowish in the merged image (h). Hb labeling intermingled with dense nuclear regions (intense DAPI staining) appears as

pink (bottom images). $\mathbf{i}-\mathbf{I}$ IVH + Haptoglobin: $\mathbf{j}$ and $\mathbf{k}$ show immunofluorescence labeling of $\mathrm{Hb}$ (red) and human $\mathrm{Hp}$ (green) following intraventricular injection of $\mathrm{Hp}$ at E29. $\mathbf{j}$ shows the widespread distribution of cell-free $\mathrm{Hb}$ (red), corresponding to that in IVH animals (f), and the domination coexistence of $\mathrm{Hp}$ in $\mathrm{K}$ (green), primarily in the molecular layer, white matter, and the EGL as shown in the merged image (I). Hp labeling was scarce in the subarachnoid space ( $\mathbf{k}$ and $\mathbf{l})$, in which Hb labeling of RBCs was extensive ( $\mathbf{j}$ and $\mathbf{l})$. Thus, the cell-free $\mathrm{Hb}$ and $\mathrm{Hp}$ are clearly distinguishable from the cell body-associated $\mathrm{Hb}$ labeling and autofluorescence. Scale bar $=50 \mu \mathrm{m}$. $\mathbf{m}$ HO-1 mRNA expression in the cerebellum was investigated at $\mathrm{P} 0$ following IVH. Following IVH, heme-degrading protein HO-1 mRNA was upregulated (IVH, dark gray bar, $n=7$ ) as compared to the controls $(n=5)$. mRNA expression for HO-1 was normalized against GAPDH and is given as fold change. The fold change values were calculated by normalizing against samples from control pups. Results are presented as box plots displaying medians and 25th and 75th percentiles. Differences between no IVH and IVH at P0 were analyzed using the Mann-Whitney $U$ test 
molecular layer. Nonspecific background staining was taken into consideration with respect to a setup threshold.

For mRNA analysis, the rabbit pups were euthanized with intracardiac thiopental injection at P0. The brain was dissected out of the skull and cerebellar tissue collected, snap-frozen, and stored at $-80{ }^{\circ} \mathrm{C}$ until further analysis as described below.

\section{RNA Isolation and Real-Time PCR}

Total RNA was extracted from the cerebellar tissue of the rabbit pups using the NucleoSpin RNA/protein extraction kit as described by the manufacturer (Macherey-Nagel, Neumann-Neander, Düren, Germany). The optical density ratio (OD at $260 \mathrm{~nm} / 280 \mathrm{~nm}$ ) of extracted RNA samples was always approximately 2.0. Reverse transcription was performed according to the manufacturer's instructions on $1 \mu \mathrm{g}$ total RNA using iScript ${ }^{\mathrm{TM}}$ cDNA Synthesis Kit (Bio-Rad, Hercules, CA, USA). The RT ${ }^{2}$ qPCR Primer Assay (primer from QIAGEN, Germantown, MD, USA) was used to quantify mRNA expression of heme oxygenase 1 (HO-1), and expression was analyzed using iTaq Universal SYBR Green Supermix (Bio-Rad). Amplification was performed as described by the manufacturer (Bio-Rad) for 40 cycles in an iCycler Thermal Cycler (Bio-Rad), and data were analyzed using iCycler iQ Optical System Software (Bio-Rad). Data were normalized to glyceraldehyde-3-phosphate dehydrogenase (GAPDH, primer from QIAGEN), with fold change values calculated by normalizing against control animals.

\section{Statistics}

Statistical analysis was performed with IBM SPSS Statistics version 22. Results are presented as medians (ranges) and displayed as box plots. Comparisons between unrelated groups were performed with the Mann-Whitney $U$ test as appropriate. Comparisons between multiple groups were made using the KruskalWallis test followed by pairwise comparison with significance values adjusted for multiple comparisons. $P$ values $<0.05$ were considered significant.

\section{Results}

\section{Extensive Presence of Cell-Free $\mathrm{Hb}$ in the Cerebellum Following IVH}

Immunofluorescence labeling of $\mathrm{Hb}$ was evaluated at $\mathrm{P} 0$ and revealed extensive deposition of RBCs in the subarachnoid space surrounding the cerebellar lobuli following IVH, which was not observed in control animals (control and IVH in Fig. 2). Labeled $\mathrm{Hb}$ was widespread within the cerebellum and not associated with cell bodies (IVH in Fig. 2). Extensive deposition of radially oriented cell-free $\mathrm{Hb}$ was observed in the deeper cerebellar layers, in the molecular layer, and in the white matter.
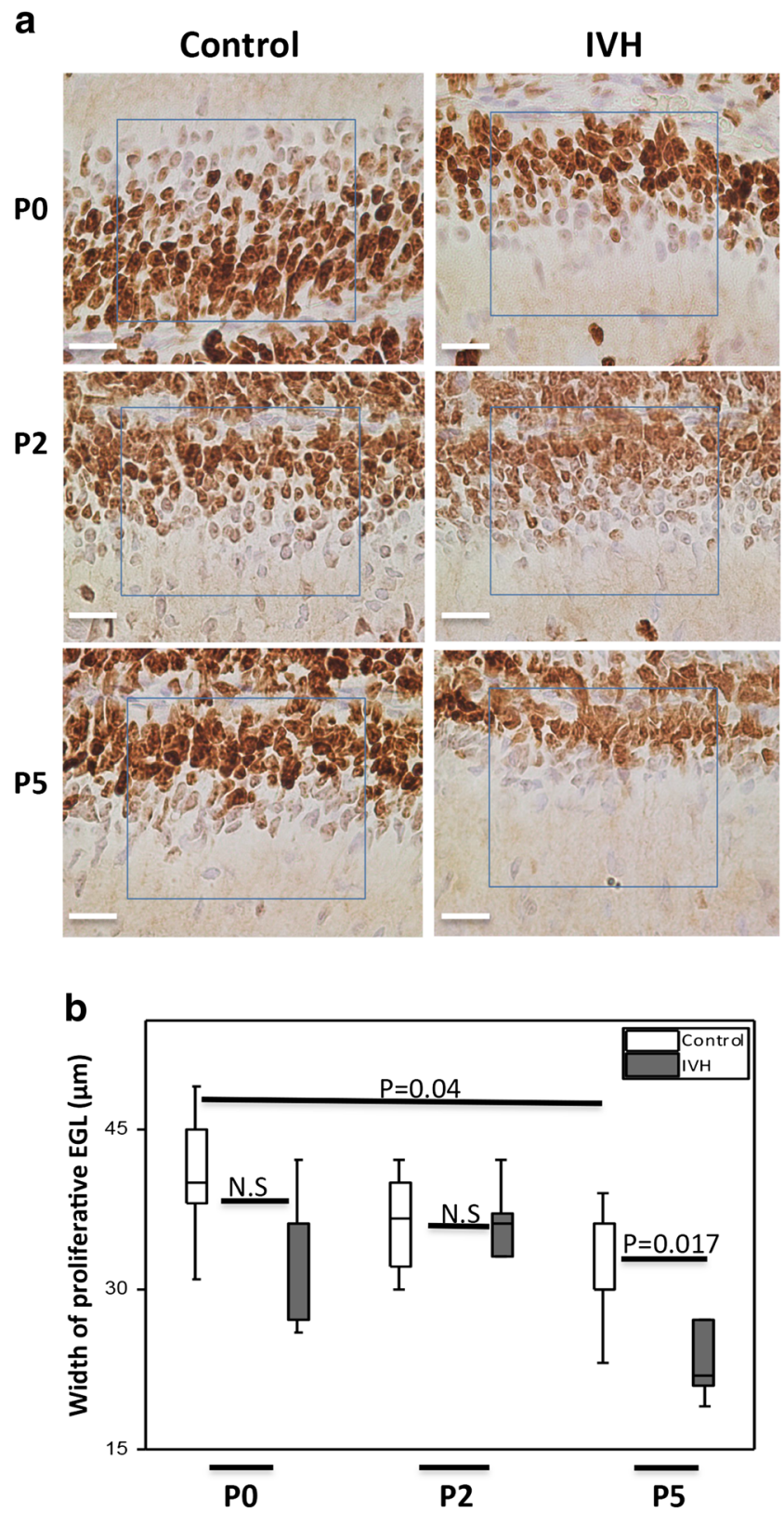

Fig. 3 Reduced width of proliferative EGL following preterm IVH. a Images of EGL of the developing cerebellum from which quantitative measurements were made of the proliferative width in the respective groups at the time points studied. The image shows the Ki67-positive outer portion of the EGL where proliferation of granule cell precursors occurs and the deeper portion, which hosts the differentiation of granule cell precursors to mature granule cells. Scale bar $=50 \mu \mathrm{m}$. b GCP proliferation in the outer portion of the EGL of the developing cerebellum was investigated following IVH by Ki67 staining. Measurement of the width of proliferative EGL was done in cerebellar tissue sections of both sham controls (control, white bars; $n$ at $\mathrm{P} 0=6, n$ at $\mathrm{P} 2=6, n$ at $\mathrm{P} 5=5$ ) and IVH pups (dark gray bars; $n$ at $\mathrm{P} 0=5, n$ at $\mathrm{P} 2=6, n$ at $\mathrm{P} 5=6$ ) at $\mathrm{P} 0$, $\mathrm{P} 2$, and P5. Results are presented as box plots displaying medians and 25th and 75th percentiles. Statistical differences between groups for respective time points were analyzed using the Mann-Whitney $U$ test 
Fig. 4 Impaired Purkinje cell maturation following preterm IVH. a Immunostaining of calbindin, a calcium-binding protein, was used as a marker of Purkinje cell development in the molecular layer of the developing cerebellum. Calbindin stains are seen as brown to dark brown. Decreased calbindin immunoreactivity was observed in IVH pups (brown) compared to controls (intense dark brown). Observation of neuronal morphology revealed smaller neuronal cell bodies and underdeveloped Purkinje dendrites in IVH pups compared to controls at postnatal time points of $\mathrm{P} 0, \mathrm{P} 2$, and $\mathrm{P} 5 . M L$ molecular layer, $P C$ Purkinje cell, $D T$ dendrites, $C B$ cell bodies; scale bar $=50 \mu \mathrm{m}$. b Grading of Purkinje cell development by measurement of percentage area of positive calbindin staining was done in cerebellar tissue sections of both control (white bars; $n$ at $\mathrm{P} 0=6, n$ at $\mathrm{P} 2=6, n$ at $\mathrm{P} 5=5$ ) and IVH pups (dark gray bars; $n$ at $\mathrm{P} 0=6, n$ at $\mathrm{P} 2=6, n$ at $\mathrm{P} 5=6$ ) at $\mathrm{P} 0, \mathrm{P} 2$, and $\mathrm{P} 5$, as described in "Materials and Methods." Results are presented as box plots displaying medians and 25th and 75th percentiles. Statistical differences between groups for respective time points were analyzed using the MannWhitney $U$ test

Relatively low amounts of cell-free $\mathrm{Hb}$ molecules were observed in the EGL and primarily in lobules in immediate proximity to large deposits of RBCs in the subarachnoid space.

To further investigate the indicated widespread presence of cell-free $\mathrm{Hb}$ in P0 IVH pups shown by immunofluorescence labeling, we performed RT-PCR analysis of mRNA expression in cerebellar tissue of the major heme-degrading protein heme-oxygenase 1 (HO-1). At P0, the HO-1 mRNA expression levels were tenfold higher in IVH pups compared to controls (Fig. 2m).

\section{EGL Proliferation Following IVH}

The total width of the EGL comprises an outer proliferative portion where the granule cell precursors (GCPs) divide and a deeper portion where the granule cells differentiate [3]. The width of the outer proliferative (Ki67positive) portion of the EGL was measured and compared between groups (Fig. 3a, b). The median (range) widths of the proliferative EGL were 36.0 (42-26), 36.0 (42-26), and $22.0(27-19) \mu \mathrm{m}$, respectively, at P0, P2, and P5 in the IVH pups and 40.0 (49-31), 36.5(42-30), and 30.0 (39-23) $\mu \mathrm{m}$, respectively, in the control pups. The median proliferative EGL width was significantly smaller in pups with IVH compared to control pups at P5 $(P=0.017)$ with a clear tendency at P0 $(P=0.08)$ (Fig. 3b).

\section{Purkinje Cell Maturation Following IVH}

Staining of calbindin, a calcium-binding protein, was used to evaluate Purkinje cell maturation in the molecular layer of the cerebellar cortex. IVH pups had smaller neuronal cell bodies and underdeveloped dendritic processes compared to control pups at P0, P2, and P5, respectively (Fig. 4a). Purkinje cell calbindin labeling was calculated and graded using densitometry, which showed that calbindin-labeled Purkinje cells at P0 a


and P2 had a significantly lower area in the IVH pups compared to controls (Fig. 4b; P0, $P=0.015$; P2, $P=0.026$ ); however, for smaller cells at $\mathrm{P} 5$, the differences were not statistically significant $(P=0.247)$. The smaller size in IVH animals indicated a reduced Purkinje cell differentiation and maturation in IVH animals. 
Fig. 5 Microglial activation in the cerebellar white matter following preterm IVH. a Immunolabeling to confirm upregulation of Iba1 (seen as brown to dark brown) expression, a marker of microglial activation was used as a qualitative marker of reactive microglia cellular response in the white matter of the developing cerebellum. Increased Iba1 immunoreactivity was observed in IVH pups compared to controls at P0, P2, and P5. Observation of microglial morphology revealed an amoeboid shape with long processes in the IVH pups. Scale bar $=50 \mu \mathrm{m}$. b Measurement of percentage area of positive Iba1 staining was done in cerebellar tissue sections of both control (white bars; $n$ at $\mathrm{P} 0=6, n$ at $\mathrm{P} 2=6, n$ at $\mathrm{P} 5=5$ ) and IVH pups (dark gray bars; $n$ at $\mathrm{P} 0=5, n$ at $\mathrm{P} 2=6, n$ at $\mathrm{P} 5=6$ ) at $\mathrm{P} 0, \mathrm{P} 2$, and $\mathrm{P} 5$, as described in "Materials and Methods." Results are presented as box plots displaying medians and 25th and 75th percentiles. Statistical differences between groups for respective time points were analyzed using the MannWhitney $U$ test

\section{Microglial Response in Cerebellar White Matter Following IVH}

Iba1 immunoreactivity was investigated to evaluate cerebellar white matter microglial response following IVH (Fig. 5a). At P0 and P2, IVH pups compared to control pups showed a significantly higher area of Iba1 immunoreactivity, based on cells with amoeboid morphology corresponding to activated microglia (P0, $P=0.009$; P2, $P=0.004$; see Fig. 5b). Microglial activation was less marked at $\mathrm{P} 5(P=0.247)$ in both groups and did not differ significantly between groups.

\section{Hp Distribution Following Intraventricular Administration}

At P0, the presence of $\mathrm{Hp}$ and its distributional relation to cellfree $\mathrm{Hb}$ was investigated in all groups by means of double immunofluorescence labeling (Fig. 2). Hp labeling was detected only in IVH pups that received intraventricular (human) $\mathrm{Hp}$ at $8 \mathrm{~h}$ of age. No Hp labeling was detected in control pups or in pups with IVH receiving only vehicle.

In $\mathrm{IVH}$ pups receiving human $\mathrm{Hp}$, the $\mathrm{Hp}$ immunolabeling was widely distributed throughout large parts of the cerebellum. Double immunofluorescence labeling of $\mathrm{Hp}$ and $\mathrm{Hb}$ in these pups displayed a high degree of co-existence of human $\mathrm{Hp}$ and $\mathrm{Hb}$ in most regions, including the molecular layer and white matter (Fig. 2, IVH + Hp). Similar to labeling of cell-free $\mathrm{Hb}$, labeling of $\mathrm{Hp}$ was relatively low in the EGL.

\section{Reduced Cerebellar Damage Following Hp Administration}

The group of pups receiving intraventricular administration of Hp following IVH (IVH $+\mathrm{Hp})$, displayed an improved Purkinje cell maturation at P0 compared to both IVH + Vehicle pups and IVH pups (Fig. 6a-d). These findings
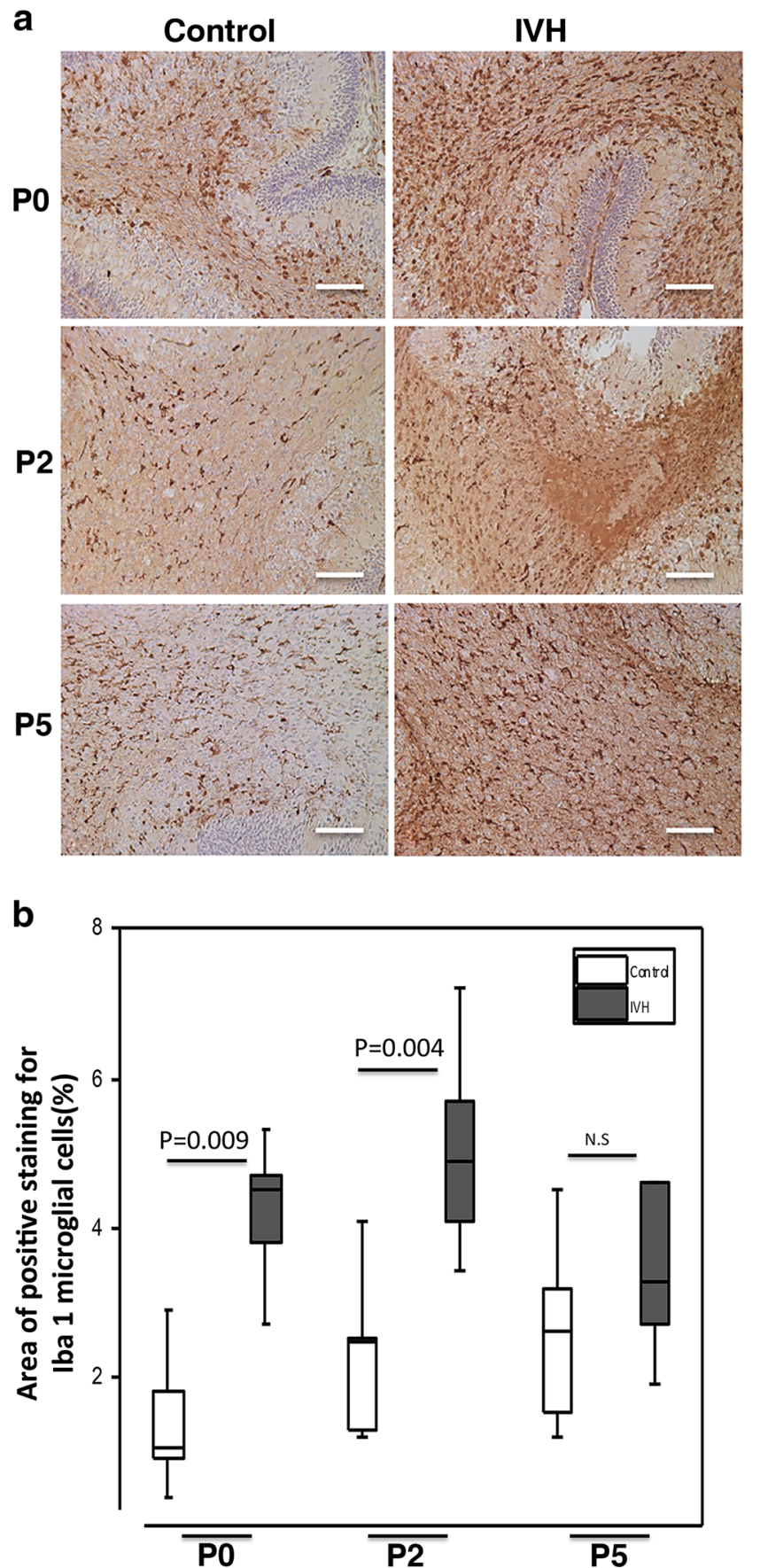

included both a higher intensity of calbindin immunoreactivity and relatively larger neuronal cell bodies with more developed dendritic processes (Fig. 6a-d). Results from quantification of Purkinje cell development by calbindin staining densitometry showed an increased staining in the IVH pups following intraventricular Hp administration (Fig. 6e; Control, $\mathrm{IVH}+\mathrm{Hp}, P=1.00$; Control, IVH + Vehicle, $P=0.024)$.

Furthermore, Hp administration restored the arrested cell proliferative activity in the outer portion of the EGL at P0 following IVH, as shown by the width of the proliferative part of the EGL in the respective treatment groups (described in 

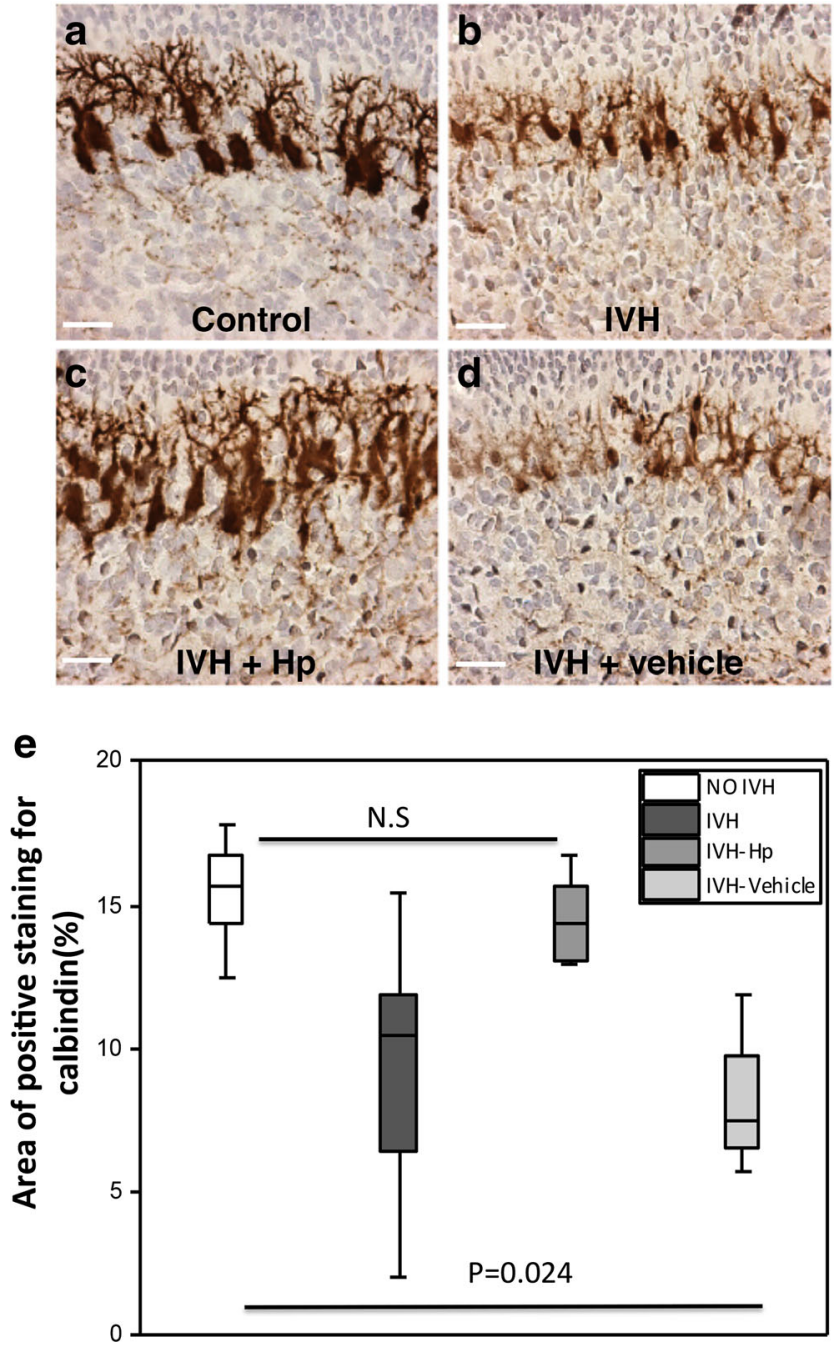

Fig. 6 Intraventricular $\mathrm{Hp}$ administration protects against impaired Purkinje cell development following preterm IVH. a-d Following intraventricular $\mathrm{Hp}$ administration at $\mathrm{P} 0$, a higher intensity of calbindin immunoreactivity, relatively larger Purkinje cell bodies, and developed dendrites were observed in the $\mathrm{Hp}$-administered IVH pups as compared to pups with IVH only or vehicle-treated IVH pups. Scale bar $=50 \mu \mathrm{m}$. e Grading of Purkinje cell development by measurement of percentage area of positive calbindin staining was done in cerebellar tissue sections at $\mathrm{P} 0$ of control pups (white bars, $n=6$ ), IVH pups (dark gray bars, $n=6$ ), and following intraventricular injection of $\mathrm{Hp}$ in pups with IVH (IVH $+\mathrm{Hp}$, gray bars, $n=6$ ) or vehicle solution (IVH + Vehicle, light gray bars, $n=4)$. Results are presented as box plots displaying medians and 25th and 75th percentiles. Differences between IVH + Hp vs. control and IVH + Vehicle vs. control were analyzed using the Kruskal-Wallis test followed by pairwise comparison with significance values adjusted for multiple comparisons

Fig. 7a-d). The median (range) widths of the proliferative EGL were 39 (48-32) $\mu \mathrm{m}$ in the IVH + Hp pups, 30.5 (3626) $\mu \mathrm{m}$ in the IVH + Vehicle pups, $36.0(42-26) \mu \mathrm{m}$ in the IVH pups, and 40.0 (49-31) $\mu \mathrm{m}$ in the control pups (Fig. 7e; Control, IVH + Hp, $P=0.93$; Control, IVH + Vehicle, $P=0.038)$.

\section{Discussion}

In this study, we show that IVH in the preterm rabbit pup is followed by an extensive deposition of blood products, specifically cell-free $\mathrm{Hb}$, in the cerebellar cortex and white matter. This event is accompanied by a decrease in neuronal cell proliferation and a delay in Purkinje cell maturation. Intraventricular administration of the cell-free $\mathrm{Hb}$ scavenger Hp resulted in a high co-existence of administered Hp with cell-free $\mathrm{Hb}$ within the cerebellum. Furthermore, administered Hp partially reversed the cerebellar damage, indicating that cell-free $\mathrm{Hb}$ and its metabolites are causal in cerebellar underdevelopment. To the best of our knowledge, this work is the first animal study to evaluate cerebellar exposure to blood products and their role in cerebellar impairment following preterm IVH.

Following preterm IVH, there is a deposition of extravasated blood into the CSF of the intraventricular space. This deposition is followed by hemolysis of RBCs, leading to a release of cell-free $\mathrm{Hb}$. Physiologically, cerebral CSF produced by the choroid plexus of the ventricular system passes through the fourth ventricle and enters the subarachnoid space, resulting in an immediate interface with the cortex of the developing cerebellum [27, 28]. Consequently, there is a strong physiological support for CSF containing extravasated blood reaching the cerebellum following cerebral IVH, as evidenced in this study by the visible presence of hemorrhagic CSF surrounding cerebellar tissue at termination of pups with IVH.

In the rabbit pup model, the spontaneous vessel rupture and the subsequent sequence of events leading to IVH mimics the situation in the human preterm infant quite well. It has been suggested that many of the effects observed in this model are related to the administered glycerol, including decreased proliferation leading to cerebellar hypoplasia [29]. Of importance in this study, as well as in our previous work, all pups including controls received the same dose of intraperitoneal glycerol, which rules out the possibility that the present findings in IVH pups are related to the administered glycerol.

Using $\mathrm{Hb}$ immunofluorescence and as demonstrated by autofluorescence, we identified an extensive deposition of $\mathrm{RBCs}$ and cell-free $\mathrm{Hb}$ in the subarachnoid space enveloping the cerebellar lobules following IVH. Cell-free $\mathrm{Hb}$ reached the innermost layers of the cerebellar cortex at $\mathrm{P} 0$ and was extensively deposited in the molecular layer and white matter of the cerebellum but to a much lesser extent in the EGL. Cell-free $\mathrm{Hb}$ within the EGL was basically found only in cerebellar lobules in immediate proximity to large deposits of RBCs in the subarachnoid space, possibly serving as a source of the cell-free $\mathrm{Hb}$. In conjunction with the radial orientation of the $\mathrm{Hb}$ molecules, the high amount of cell-free $\mathrm{Hb}$ in the molecular layer and white matter suggests additional sources beyond the CSF in the subarachnoid space. Speculatively, the source of cell-free $\mathrm{Hb}$ could be via the roof of the fourth ventricle and 
Fig. 7 Intraventricular $\mathrm{Hp}$ administration protects against reduction in width of proliferative EGL following preterm IVH. a-d Following intraventricular $\mathrm{Hp}$ administration at $\mathrm{P} 0$, a higher intensity of Ki67

immunoreactivity was observed in the Hp-administered IVH pups as compared to pups with IVH only or vehicle-treated IVH pups. Scale bar $=20 \mu \mathrm{m}$. e

Measurement of the width of Ki67-positive proliferative EGL was performed in cerebellar tissue sections at $\mathrm{P} 0$ of control pups (white bars, $n=6$ ), IVH pups (dark gray bars, $n=5$ ), and following intraventricular injection of $\mathrm{Hp}$ in pups with IVH $(\mathrm{IVH}+\mathrm{Hp}$, gray bars, $n=5)$ or vehicle solution (IVH + Vehicle, light gray bars, $n=4)$. Results are presented as box plots displaying medians and 25th and 75th percentiles. Differences between $\mathrm{IVH}+\mathrm{Hp}$ vs. control and IVH + Vehicle vs. control were analyzed using the Kruskal-Wallis test followed by pairwise comparison with significance values adjusted for multiple comparisons


transfer through the cerebellar peduncles to the white matter of the cerebellum.

Cell-free $\mathrm{Hb}$ and its metabolites, e.g., heme and iron, are well described to act as sources of ROS and free radicals, which are causal initiators of oxidative damage to cells and tissues [30]. We have previously shown that cell-free $\mathrm{Hb}$ and its metabolites, i.e., methemoglobin and heme, are potent inducers of pro-inflammatory pathways in choroid plexus epithelium and in astrocytes [17-19]. The extensive presence of cell-free $\mathrm{Hb}$ in the cerebellar white matter following IVH in this study was accompanied by clear signs of microglial activation in corresponding white matter regions, marked by increased expression of Ibal antigen and an activated morphology in the IVH group (Fig. 5). This result suggests that deposited cell-free $\mathrm{Hb}$ may induce a microglial pro-inflammatory response with possible 
adverse effects on immature oligodendrocyte proliferation and maturation and subsequent cerebellar white matter damage. In the current study, using immunofluorescence and immunohistochemistry, we could not distinguish between different forms of oxidized $\mathrm{Hb}$, e.g., oxyHb and metHb, and thus cannot conclude whether the effects observed are caused by oxyHb, metHb, or the downstream metabolites heme and iron.

Our finding that cell-free $\mathrm{Hb}$ is extensively deposited in the molecular layer of the cerebellum is a cause for concern because this layer constitutes the environment for Purkinje cell maturation. The Purkinje cells are intrinsically sensitive to oxidative stress and essential for establishing the cerebellar circuitry, which is vital for impulse transmission in the cerebellum [31-34]. In addition, mature Purkinje cells also play a vital role in the development of the EGL by sourcing GCPs with sonic hedgehog protein, an important mitotic growth factor vital to their proliferation $[35,36]$. Consequently, exposure of the molecular layer to cell-free $\mathrm{Hb}$ not only will have neurotoxic effects on Purkinje cells but also will further impair the development of the EGL. The EGL of the developing cerebellum serves as a germinal center where GCPs proliferate and subsequently differentiate into mature granule cells. Granule cells are important for the structural integrity of the cerebellum; in addition, during their migration to form the granular layer, they transmit certain excitatory signals needed for the differentiation and maturation of the Purkinje cells. Thus, exposure of the developing cerebellum to cell-free $\mathrm{Hb}$ may lead to damaging effects not only to the cellular architecture but also to the functional integrity of the cerebellum, subsequently causing cerebellar underdevelopment.

To evaluate the possible effects of impaired Purkinje cell support and direct exposure to the hemorrhage, we performed metric analysis of Ki67 staining to evaluate EGL cell proliferation and thus pathological cellular senescence. Cellular senescence in this context can be seen as a process by which damage to tissue causes a decrease in metabolism leading to arrest of cell proliferation and recruitment of phagocytic immune cells to help in tissue renewal [37]. Measurements of the EGL (Fig. 3a) showed that IVH caused a significant decrease in the width of the proliferative portion of the EGL at P0 and P5 (Fig. 3b). This result is a clear indication that IVH-related processes cause impairment of the proliferative activity of the EGL. The postnatal time points $\mathrm{P} 0$ to $\mathrm{P} 5$ studied in the preterm rabbit pup correspond to the gestational ages of 25 to 35 weeks in humans, a period characterized by intense cell proliferation in the outer portion of the EGL [38]. In the human preterm infant, the width of the proliferative EGL decreases from 30 gestational weeks onwards as the GCPs mature into granule cells and leave the EGL to form the internal granular layer [3]. This timing corresponds well to our observations in the rabbit pup with EGL proliferative width in control pups showing a decrease in width from P0 to P5 (Fig. 3b).
Cell-free $\mathrm{Hb}$ may cause damage to the cerebellum in a number of different ways. Following hemolysis, release of excess cell-free $\mathrm{Hb}$ may lead to the formation of heme and free iron, increasing the concentration of redox-active iron in the extracellular environment. Both heme and free iron have a pro-oxidative damaging effect on cells, and iron overload has been reported to cause cerebral damage following IVH [39, 40]. Indeed, reduction in iron overload attenuated development of hydrocephalus and brain damage in a rodent model of neonatal germinal matrix hemorrhage [41]. In addition to its redox-related effects, cell-free $\mathrm{Hb}$ also acts as a redox-active damage-associated molecular pattern (known as DAMP) molecule that perturbs the innate immune homeostasis by triggering Toll-like receptor signal transduction pathways and causing pro-inflammatory damage to cells [42-44]. In this study, we investigated the causal importance of cell-free $\mathrm{Hb}$ in the impairment of Purkinje cell maturation and in the arrest of EGL cell proliferation by administering the $\mathrm{Hb}$-scavenging protein $\mathrm{Hp}$ intraventricularly following detection of IVH. Hp binds to cell-free $\mathrm{Hb}$, forming an inert $\mathrm{Hb}-\mathrm{Hp}$ complex, which then channels the $\mathrm{Hb}$ molecules for intracellular degradation via CD163-mediated endocytosis [45, 46]. Intracellularly, the enzyme HO-1 breaks down heme to bilirubin and CO, both of which have antioxidant and vasodilatory benefits [47]. By forming a tight complex with cell-free $\mathrm{Hb}, \mathrm{Hp}$ stabilizes and shields heme iron within the hydrophobic pocket of $\mathrm{Hb}$, thereby preventing its cytotoxic and pro-oxidative effect [48]. The removal of cell-free $\mathrm{Hb}$ from the extracellular environment through its complex formation with $\mathrm{Hp}$ could thus reduce interaction with signal-transducing receptors of cells in the brain innate immune system and reduce exposure to excess iron and to heme-induced toxicity.

A neuroprotective role of induced endogenous Hp following intracerebral hemorrhage has been documented [49]. The induction of $\mathrm{Hp}$ was necessary because of very low levels of endogenous $\mathrm{Hp}$ in the human brain. In a previous study, the resting state capacity of the intrathecal $\mathrm{Hb}-\mathrm{Hp}$ complex clearance was found to be 50,000-fold lower than that in the circulation in the adult. The system was quickly saturated during $\mathrm{SAH}$ with a residual inability to deal with cell-free $\mathrm{Hb}$, clearly indicating an insufficient $\mathrm{Hb}$ scavenging capacity within the brain [50]. In view of this, we administered human Hp intraventricularly, which resulted in an extensive presence of $\mathrm{Hp}$ in the cerebellum. Hp was not detected in animals that did not receive exogenous Hp. The Hp labeling was specific for the administered human Hp, i.e., completely absent in shaminjected IVH pups as in IVH and control pups, thus excluding endogenous Hp as a source of the positive Hp labeling.

Our double immunofluorescence of $\mathrm{Hb}$ and $\mathrm{Hp}$ showed that the injected Hp reaches the same cerebellar areas as cell-free $\mathrm{Hb}$ and that the two are extensively co-localized in these regions. $\mathrm{Hb}$ and administered $\mathrm{Hp}$ co-existed in several regions of the cerebellum, mainly within the molecular layer 
and white matter and to a lesser degree in the EGL. Congruent with the anatomical co-existence of $\mathrm{Hp}$ and $\mathrm{Hb}$, results showed that $\mathrm{Hp}$ administration partially reduced the Purkinje cell maturational arrest caused by IVH, represented by calbindin immunoreactivity showing a higher intensity of labeling, relatively larger cell bodies, and more extensive dendritic processes in pups receiving $\mathrm{Hp}$ as compared to the other IVH groups. Furthermore, Hp administration counteracted the decreased development of the proliferative region of the EGL following IVH and increased the proliferative width almost to the level of the control pups.

\section{Conclusion}

In this study, we showed that IVH in the preterm rabbit pup is followed by an extensive deposition of cell-free $\mathrm{Hb}$ in cerebellar cell layers and white matter. This exposure to cell-free $\mathrm{Hb}$ was associated with microglial activation, an arrest in neuronal cell proliferation, and a delayed Purkinje cell maturation. Intraventricular administration of the cell-free $\mathrm{Hb}$ scavenger $\mathrm{Hp}$ partially blocked these effects, suggesting that cell-free $\mathrm{Hb}$ and its downstream metabolites are causal in cerebellar impairment following IVH. In terms of future clinical application, these results suggest that removal or scavenging of $\mathrm{Hb}$ metabolites following IVH, for instance by administered $\mathrm{Hp}$, may reduce subsequent cerebellar impairment.

BSA, bovine serum albumin; EGL, external granular layer; GAPDH, glyceraldehyde-3-phosphate dehydrogenase; GCP, granular cell precursor; $\mathrm{Hb}$, hemoglobin; $\mathrm{Hp}$, haptoglobin; IVH, intraventricular hemorrhage; PBS, phosphate buffer saline; PFA, paraformaldehyde; SAH, subarachnoid hemorrhage

Acknowledgements This work was supported by the Swedish Research Council, governmental ALF research grants to Lund University and Lund University Hospital, the European Commission (FP7, Project 305485 PREVENT-ROP), the Crafoordska Foundation, the Greta and Johan Kock Foundation, the Alfred Österlund Foundation, the Erasmus+ programme of the European Union (Framework Agreement Number: 2013-0040), and the Fanny Ekdahls Foundation. The authors wish to acknowledge Carin Sjölund, Lund University, for excellent technical assistance.

\section{Compliance with Ethical Standards}

Conflict of Interest All authors declare that they have no conflict of interest.

Ethical Approval All applicable national and institutional guidelines for the care and use of animals were followed.

Open Access This article is distributed under the terms of the Creative Commons Attribution 4.0 International License (http:// creativecommons.org/licenses/by/4.0/), which permits unrestricted use, distribution, and reproduction in any medium, provided you give appropriate credit to the original author(s) and the source, provide a link to the Creative Commons license, and indicate if changes were made.

\section{References}

1. Ballabh P. Intraventricular hemorrhage in premature infants: mechanism of disease. Pediatr Res. 2010;67:1-8.

2. Schmahmann JD, Smith EE, Eichler FS, Filley CM. Cerebral white matter: neuroanatomy, clinical neurology, and neurobehavioral correlates. Ann N Y Acad Sci. 2008;1142:266-309.

3. Volpe JJ. Cerebellum of the premature infant: rapidly developing, vulnerable and clinically important. J Child Neurol. 2009;24:1085104.

4. Parker J, Mitchell A, Kalpakidou A, Walshe M, Jung HY, Nosarti $\mathrm{C}$, et al. Cerebellar growth and behavioural \& neuropsychological outcome in preterm adolescents. Brain. 2008;131:1344-51.

5. Limperopoulos C, Chilinaryan G, Sullivan N, Guizard N, Robertson RL, Du Plessis AJ. Injury to the premature cerebellum: outcome is related to remote cortical development. Cereb Cortex. 2014;24:728-36.

6. Kitai Y, Hirai S, Ohmura K, Ogura K, Arai H. Cerebellar injury in preterm children with cerebral palsy after intraventricular hemorrhage: prevalence and relationship to functional outcomes. Brain and Development. 2015;37:758-63.

7. Tam EW, Miller SP, Studolme C, Chau V, Glidden D, Poskitt KJ, et al. Differential effects of intraventricular hemorrhage and white matter injury on preterm cerebellar growth. J Pediatr. 2011;158: 366-71.

8. Limperopoulos C, Soul JS, Gauvreau K, Huppi PS, Warfield SK, Bassan $\mathrm{H}$, et al. Late gestation cerebellar growth is rapid and impeded by premature birth. Pediatrics. 2005a;115:688-95.

9. Messerschimdt A, Prayer D, Brugger PC, Boltshauser E, Zoder G, Sterniste W, et al. Preterm birth and disruptive cerebellar development: assessment of perinatal risk factors. Eur J Paediatr Neurol. 2008; 12:455-60.

10. Limperopoulos CS, Haidar H, Huppi PS, Bassan H, Warfield SK, Robertson RL, et al. Impaired trophic interactions between the cerebellum and the cerebrum among preterm infants. Pediatrics. 2005b;116:844-50.

11. Van Kooij BJ, Benders MJ, AnbeeK P, Van Haastert IC, De Vries LS, Groenendaal F. Cerebellar volume and proton magnetic resonance spectroscopy at term, and neurodevelopment at 2 years of age in preterm infants. Dev Med Child Neurol. 2012;54:260-6.

12. Tam EW. Potential mechanisms of cerebellar hypoplasia in prematurity. Neuroradiology. 2013;55(Suppl 2):41-6.

13. Nosarti C, Giouroukou E, Micali N, Rifkin L, Morris RG, Murray RM. Impaired executive functioning in young adults born very preterm. J Int Neuropsychol Soc. 2007;13:571-81.

14. Indredavik MS, Vik T, Evensen KA, Skranes J, Taraldsen G, Brubakk AM. Perinatal risk and psychiatric outcome in adolescents born preterm with very low birth weight or term small for gestational age. J Dev Behav Pediatr. 2010;31:286-94.

15. Lee JY, Keep RF, He Y, Sagher O, Hua Y, Xi G. Hemoglobin and iron handling in brain after subarachnoid hemorrhage and the effect of deferoxamine on early brain injury. J Cereb Blood Flow Metab. 2010;30:1793-803.

16. Lok J, Leung W, Murphy S, Butler W, Noviski N, Lo EH. Intracranial hemorrhage: mechanisms of secondary brain injury. Acta Neurochir Suppl. 2011;111:63-9.

17. Gram M, Sveinsdóttir S, Ruscher K, Hansson SR, Cinthio M, Åkerström B, et al. Hemoglobin induces inflammation after preterm intraventricular hemorrhage by methemoglobin formation. $\mathrm{J}$ Neuroinflammation. 2013;10:100.

18. Gram M, Sveinsdóttir S, Cinthio M, Sveinsdóttir K, Hansson SR, Mörgelin M, et al. Extracellular hemoglobin - mediator of inflammation and cell death in the choroid plexus following preterm intraventricular hemorrhage. J Neuroinflammation. 2014;11:200. 
19. Sveinsdóttir S, Gram M, Cinthio M, Sveinsdóttir K, Mörgelin M, Ley D. Altered expression of aquaporin 1 and 5 in the choroid plexus following preterm intraventricular hemorrhage. Dev Neurosci. 2014;36:542-51.

20. Ley D, Romantsik O, Vallius S, Sveinsdottir K, Sveinsdottir S, Agyemang AA, et al. High presence of extracellular hemoglobin in the periventricular white matter following preterm intraventricular hemorrhage. Front Physiol. 2016;7:330.

21. Kumar S, Bandyopadhyay U. Free heme toxicity and its detoxification systems in human. Toxicol Lett. 2005;157:175-88.

22. Olsson MG, Allhorn M, Bulow L, Hansson SR, Ley D, Olsson ML, et al. Pathological conditions involving extracellular hemoglobin: molecular mechanisms, clinical significance, and novel therapeutic opportunities for alpha (1)-microglobulin. Antioxid Redox Signal. 2012;17:813-46.

23. Quaye IK. Extracellular hemoglobin: the case of a friend turned foe. Front Physiol. 2015;6:96.

24. Sveinsdóttir S, Cinthio M, Ley D. High-frequency ultrasound in the evaluation of cerebral intraventricular haemorrhage in preterm rabbit pups. Ultrasound Med Biol. 2012;38:423-31.

25. Georgiadis $\mathrm{P}, \mathrm{Xu} \mathrm{H}$, Chua $\mathrm{C}, \mathrm{Hu} \mathrm{F}$, Collins L, Huynh C, et al. Characterization of acute brain injuries and neurobehavioral profiles in a rabbit model of germinal matrix hemorrhage. Stroke. 2008;39:3378-88.

26. Chua CO, Chahboune H, Braun A, Dummula K, Chua CE, Yu J, Ungvari Z, et al. Consequences of intraventricular hemorrhage in a rabbit pup model. Stroke. 2009;40:3369-77.

27. Ballabh P. Pathogenesis and prevention of intraventricular hemorrhage. Clin Perinatol. 2014;41:47-67.

28. Sakka L, Coll G, Chazal J. Anatomy and physiology of cerebrospinal fluid. Eur Ann Otorhinolaryngol Head Neck Dis. 2011;128: 309-16.

29. Traudt CM, Mcpherson RJ, Studholme C, Millen KJ, Juul SE. Systemic glycerol decreases neonatal rabbit brain and cerebellar growth independent of intraventricular hemorrhage. Pediatr Res. 2014:75:389-94.

30. Khaket TP, Ahmad R. Biochemical studies on hemoglobin modified with reactive oxygen species (ROS). Appl Biochem Biotechnol. 2011;164:1422-30.

31. Lopez IA, Acuna D, Beltran-Parrazal L, Lopez IE, Amarnani A, Cortes M, et al. Evidence for oxidative stress in the developing cerebellum of the rat after chronic mild carbon monoxide exposure (0.0025\% in air). BMC Neurosci. 2009;10:53.

32. Hsieh JY, Ulrich B, Issa FA, Wan J, Papazian DM. Rapid development of Purkinje cell excitability, functional cerebellar circuit, and afferent sensory input to cerebellum in zebrafish. Front Neural Circuits. 2014;8:147.

33. White JJ, Arancillo M, Stay TL, George-Jones NA, Levy SL, Heck $\mathrm{DH}$, et al. Cerebellar zonal patterning relies on Purkinje cell neurotransmission. J Neurosci. 2014;34:8231-45.
34. Sillitoe RV. Mossy fibers terminate directly within Purkinje cell zones during mouse development. Cerebellum. 2016;15:14-7.

35. Carletti B, Rossi F. Neurogenesis in the cerebellum. Neuroscientist. 2008;14:91-100.

36. De Luca A, Cerrato V, Fuca E, Parmigiani E, Buffo A, Leto K. Sonic hedgehog patterning during cerebellar development. Cell Mol Life Sci. 2016;73:291-303.

37. Munoz-Espin D, Serrano M. Cellular senescence: from physiology to pathology. Nat Rev Mol Cell Biol. 2014;15:482-96.

38. Clancy B, Finlay BL, Darlington RB, Anand KJ. Extrapolating brain development from experimental species to humans. Neurotoxicology. 2007;28:931-7.

39. Chen Z, Gao C, Hua Y, Keep RF, Muraszko K, Xi G. The role of iron in brain injury after intraventricular hemorrhage. Stroke. 2011;42(2):465-70.

40. Strahle JM, Garton T, Bazzi AA, Kilaru H, Garton HJL, Maher CO, et al. Role of hemoglobin and iron in hydrocephalus after neonatal intraventricular hemorrhage. Neurosurgery. 2014;75(6):696-706.

41. Guo J, Chen Q, Tang J, Zhang J, Tao Y, Li L, et al. Minocyclineinduced attenuation of iron overload and brain injury after experimental germinal matrix hemorrhage. Brain Res. 2015;1594:11524

42. Ding JL, Lee SK. A perspective on the role of extracellular hemoglobin on the innate immune system. DNA Cell Biol. 2013;32:3640.

43. Gladwin MT, Ofori-Acquah SF. Erythroid DAMPS drive inflammation SCD. Blood. 2014;123(24):3689-90.

44. Wang YC, Zhou Y, Fang H, Lin S, Wang PF, Xiong RP, et al. Tolllike receptor $2 / 4$ heterodimer mediates inflammatory injury in intracerebral hemorrhage. Ann Neurol. 2014;75:876-89.

45. Abraham NG, Drummond G. CD163-mediated hemoglobin-heme uptake activates macrophage $\mathrm{HO}-1$, providing an antiinflammatory function. Circ Res. 2006;99:911-4.

46. Chintagari NR, Nguyen J, Belcher JD, Vercellotti GM, Alayash AI. Haptoglobin attenuates hemoglobin-induced heme oxygenase-1 in renal proximal tubule cells and kidneys of a mouse model of sickle cell disease. Blood Cells Mol Dis. 2015;54:302-6.

47. Ryter SW, Morse D, Choi AM. Carbon monoxide and bilirubin: potential therapies for pulmonary/vascular injury and disease. Am J Respir Cell Mol Biol. 2007;36:175-82.

48. Yang F, Haile DJ, Berger FG, Herbert DC, Van Beveren E, Ghio AJ. Haptoglobin reduces lung injury associated with exposure to blood. Am J Physiol Lung Cell Mol Physiol. 2003;284:402-9.

49. Zhao X, Song S, Sun G, Strong R, Zhang J, Grotta JC, Aronowski J. Neuroprotective role of haptoglobin after intracerebral hemorrhage. J Neurosci. 2009;29(50):15819-27.

50. Galea J, Cruickshank G, Teeling JL, Boche D, Garland P, Perry VH, et al. The intrathecal CD163-haptoglobin-hemoglobin scavenging system in subarachnoid hemorrhage. J Neurochem. 2012;121:78592. 